Markus Knorz*, Peter Niemz and Jan-Willem van de Kuilen

\title{
Measurement of moisture-related strain in bonded ash depending on adhesive type and glueline thickness
}

\begin{abstract}
Structural wood-adhesive bonds (WAB) have to be durable while subjected to considerable stresses caused by mechanical loads and moisture content changes. To better understand the moisture-related durability of WABs, knowledge is important of how moisture changes generate strain in the bond. In this paper, strain on endgrain surfaces of bonded ash specimens was analyzed by means of digital image correlation. Strains were generated by wood shrinkage, and the evaluation was focused on shear strain (SStr). The bond lines were studied depending on the adhesive type - phenol resorcinol formaldehyde (PRF), melamine urea formaldehyde (MUF), polyurethane (PUR), and emulsion polymer isocyanates (EPI). Moreover, three different glueline (GL) thicknesses of MUF were taken into consideration. Comparing the adhesive types, SStr distributions (SStrD) were strongly influenced by adhesive elasticity. MUF and PRF bonds were quite rigid and were associated with pronounced strain amplitudes in and close to the GL together with strain dissipation reaching deep in the wood. PUR and EPI adhesives were more elastic and therefore allowed for smoother strain transition showing less distinct strain peaks. GL thickness had significant impact on SStrD. A high strain level and direct strain transition between adherends was found for the $0.01 \mathrm{~mm} \mathrm{GL}$, whereas a pronounced strain decrease was observed in the 0.1 and $0.2 \mathrm{~mm}$ GLs. This indicates different stress levels in the wood-adhesive interface dependent on GL thickness.
\end{abstract}

Keywords: adhesive, ash, digital image correlation, EPI, glueline thickness, moisture-induced strain, MUF, PRF, PUR

*Corresponding author: Markus Knorz, Holzforschung München (TU München), Winzererstrasse 45, 80797 Munich, Germany, e-mail: knorz@hfm.tum.de

Peter Niemz: Institute for Building Materials, ETH Zurich, Wood Physics Group, $\mathrm{CH}-8093$ Zurich, Switzerland

Jan-Willem van de Kuilen: Holzforschung München (TU München), Winzererstrasse 45, 80797 Munich, Germany; and Delft University of Technology, Faculty of Civil Engineering and Geosciences,

Stevinweg 1, 2628 CN Delft, The Netherlands
DOI 10.1515/hf-2014-0324

Received October 30, 2014; accepted March 12, 2015; previously published online April 14, 2015

\section{Introduction}

Adhesive bonds in timber structures must be durable and stable. The durability of wood-adhesive bonds (WAB) is affected by the climate and can be impaired by induced swelling and shrinkage stresses in wood and WABs due to moisture changes. Stresses can develop at the beginning of the service life during the initial hygrothermal conditioning of the product when lamellas with different moisture content (MC) are adhesively bonded (Niemz et al. 2005). In addition, stresses can occur as a consequence of MC differences, for example, when lamellas with relatively high MC are bonded and MC decreases to a seasonal minimum in winter. Stresses are also generated when laminated timber is subjected to varying temperature and humidity during service life. When stresses exceed bond strength, delaminations can develop and affect the remaining service life (van de Kuilen and Gard 2013). Although the importance of moisture-dependent behavior of structurally laminated timber is recognized and has been examined in several studies (e.g., Aicher et al. 1998; Jönsson and Svensson 2004; Gereke and Niemz 2010; Angst and Malo 2012), the moisture-related durability (MRD) of WABs is still not well understood.

The level of moisture-induced stresses in WABs depends on various factors, such as the geometrical properties of the lamellas and the glued element as well as the wood species. With increasing density, shrinkage, and swelling coefficients as well as stiffness and strength properties, moisture changes generate higher stress levels (Marra 1992). Bonds between high-density wood have to tolerate higher moisture-induced stresses than those between lower-density wood. In addition, the strength difference between wood and WAB is lower for wood species with higher density; therefore, it is more likely that bond failure occurs than with low-density wood 
species. This effect gained importance when developing high-capacity glulam made of ash (Fraxinus excelsior L.) or beech (Fagus sylvatica L.), because these wood species have significantly higher densities than other woods typically used for glulam in Europe [e.g., spruce (Picea abies L. Karst.)]. Although the properties of ash and beech are beneficial for the load-carrying capacity, it is difficult to obtain high moisture-related bond durability (MRBD) with these species (Ohnesorge et al. 2010; Schmidt et al. 2010; Knorz et al. 2014). In the quoted studies, delamination tests were in focus that generate stresses on the WAB both perpendicular to the grain and in shear to evaluate MRBD. In addition, investigations with adhesively bonded hardwood (HW) were performed aiming at the determination of factors that influence MRD. On a microscopic scale, the glueline (GL) thickness with dimensions up to $0.2 \mathrm{~mm}$ (Knorz et al. 2014), the surface texture (Knorz et al. 2015), and the application of a primer (Kläusler et al. 2014) showed an impact on MRBD.

The results of the latter studies indicate that strain distribution (StrD) in the GL and in its vicinity has significant impact on MRBD. This was also proposed by Frihart and Wescott (2008) and Frihart (2009), who developed a model that explains the distribution of swelling strain in the case of moisture absorption for two different adhesive types. According to this model, "in situ polymerized" adhesives, such as phenol resorcinol formaldehyde (PRF) and melamine urea formaldehyde (MUF), penetrate into the cell walls and stabilize them and, in addition, develop a rigid GL. Swelling strain is then distributed away from the wood-adhesive interface and dissipated in the wood. In contrast, "pre-polymerized" adhesives [e.g., polyurethanes (PUR) and emulsion polymer isocyanate (EPI)] do not penetrate into cell walls and produce a more flexible GL that results in a different StrD. This model is supported by several experimental studies aiming at the analysis of adhesive penetration into cell walls (Gindl et al. 2002, 2004) and the determination of material properties of adhesives (Konnerth et al. 2006, 2007; Follrich et al. 2010; Clauß et al. 2011). Konnerth et al. (2010) and Kläusler et al. (2013) demonstrated that the mechanical properties of cured adhesives depend on their MC and therefore have to be considered in the case of moisture change. To investigate the influence of adhesive penetration into cell walls and cell lumens on the stress distribution in WABs, Gindl et al. (2005) compared PRF- and PUR-bonded spruce in compression tests perpendicular to the grain. It was shown that compression strain was reduced in the GL area compared to wood and that strain in the GL area was lower for PRF than for PUR. This is in agreement with the data of Müller et al. (2005), who observed higher deformation for PUR-bonded than for PRF-bonded lap joint shear specimen, and these results were explained with different Young's moduli of the adhesives.

The delamination tests with HW and several studies quoted above indicate that StrD has a significant impact on MRBD. However, little is known about the complex micromechanics in WABs and how strains are distributed as a result of moisture change. Therefore, the goal of the present study is to examine moisture-induced strain in adhesively bonded ash wood, taking different GL thicknesses in a relevant range between 0.01 and $0.2 \mathrm{~mm}$ and adhesive types (PRF, MUF, PUR, and EPI) into account. The specimens are designed with a primary focus on investigating shear strain (SStr) in the GL area. For strain measurements, digital image correlation (DIC) will be applied. DIC is well suited for the visualization of strains with a high spatial resolution on wood surfaces (Zink et al. 1995; Valla et al. 2011; Keunecke et al. 2012; Lanvermann et al. 2014a) and wood-adhesive joints (Serrano and Enquist 2005). The expectation of the present study is that a better comprehension of stress fields in WABs due to moisture changes will contribute to adhesive developments, numerical simulations of WABs, and a better understanding of the durability of laminated timber under varying climatic conditions.

\section{Materials and methods}

Defect-free ash boards were selected with tangentially ( $\mathrm{T}$ ) oriented growth rings and dimensions $40 \times 185 \times 550 \mathrm{~mm}^{3}$ (thickness $\times$ width $\times$ length). After storage at $20^{\circ} \mathrm{C}$ and $95 \%$ relative humidity (RH; 20/95) for approximately 8 weeks, the mean MC before bonding was $19.7 \%$ with $0.6 \%$ SD. The density averaged $618 \mathrm{~kg} \mathrm{~m}^{-3}$ with $46 \mathrm{~kg} \mathrm{~m}^{-3}$ $\mathrm{SD}$ (related to $12 \% \mathrm{MC}$ ). The boards were planed to a cross-section of $180 \times 30 \mathrm{~mm}^{2}$ and cut into pieces with $80 \mathrm{~mm}$ length. The members were assembled from three pieces (Figure 1) with the same growth ring orientation. This assembly agrees with the specimen layup applied in delamination tests according to EN 302-2 (2013) for MRBD evaluation. The members were bonded with four adhesives (PRF, MUF, PUR, and EPI), which are approved for load-bearing softwood bonds in Europe. The GL thickness $d_{\mathrm{gl}}$ of $0.1 \mathrm{~mm}$ was generated by means of an aluminum frame for all four adhesives. In addition, MUF-bonded members with $d_{\mathrm{gl}}$ of 0.01 and $0.2 \mathrm{~mm}$ were prepared. From each bonded member, one specimen with $150 \mathrm{~mm}$ width, approximately $90 \mathrm{~mm}$ height, and $15 \mathrm{~mm}$ length (Figure 1) was obtained. For each adhesive and GL thickness, five specimens were tested, which corresponds to a total number of 30 specimens.

The bonding parameters open assembly time $(<5 \mathrm{~min})$, pressure (1.2 MPa), press time (12 h), one-sided application, and bonding conditions (20/95) were constant for all adhesives. The amount of adhesive applied for the $0.01 \mathrm{~mm}$ MUF GL $\left(\mathrm{GL}_{0.01}\right)$ was $450 \mathrm{~g} \mathrm{~m}^{-2}$. The 0.1 and $0.2 \mathrm{~mm} \mathrm{GLs}\left(\mathrm{GL}_{0.1}, \mathrm{GL}_{0.2}\right)$ were prepared with an excess of adhesive. Further data of adhesive properties and processing parameters are summarized in Table 1. 
a

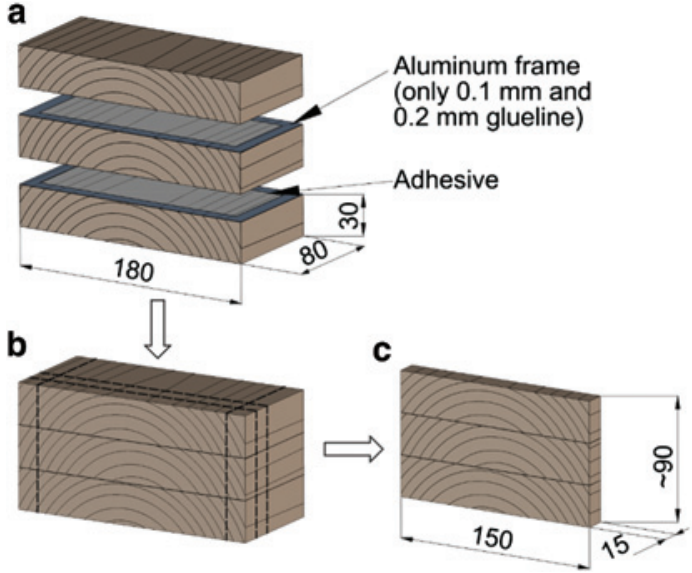

Figure 1: Schematic drawing of specimen preparation: (a) assembly of boards with the application of adhesive and aluminum frame for defined GL thickness as required, (b) cutting of test specimen from bonded assembly, and (c) test specimen.

Table 1: Adhesive properties and processing parameters for the four adhesives indicated.

\begin{tabular}{lrrrr}
\hline Adhesive & MUF & PRF & PUR & EPI \\
\hline Ratio resin/hardener (-) & $100 / 50$ & $100 / 20$ & $\mathrm{n} / \mathrm{a}$ & $100 / 15$ \\
Solid content (\%) $^{\mathrm{a}}$ & 50.2 & 55.8 & 100 & 66.4 \\
Closed assembly time (min) & $30\left(\mathrm{GL}_{0.01}\right)$ & 80 & 5 & 10 \\
& $70\left(\mathrm{GL}_{0.1-0.2}\right)$ & & & \\
\hline
\end{tabular}

a Solid content for MUF, PRF, and EPI was determined according to EN 827 (2005); value for PUR corresponds to the manufacturers' declaration.

For strain measurement by DIC, an artificial speckle pattern was applied on one end-grain surface of the specimens. The approach to analyze end-grain surfaces corresponds to that of standardized delamination tests for MRD evaluation. The speckle pattern was generated with acrylic paint sprayed with an airbrush and comprised a white base layer and a layer of stochastically distributed dark speckles. The experimental setup consists of a specimen mount, two cameras, and cold light sources for illumination (Figure 2). The surface observed was aligned perpendicular to the optical axes (z) of the cameras.

The specimens were placed on three supports and images were taken from underneath. This setup guaranteed a constant distance between measurement surface and the cameras, thus avoiding errors because of dimensional change of the specimens in the z-direction. In the $\mathrm{x}$ - and $\mathrm{y}$-directions (Figure 2), the specimens were positioned by means of aligning pins to provide consistency. The two cameras recorded monochrome images $(2048 \times 2048$ pixels $)$ of an overall specimen view (image size: $160.6 \times 160.6 \mathrm{~mm}^{2}$, pixel size: $78.4 \times 78.4 \mu \mathrm{m}^{2}$ ) and a detailed view of a corner area (image size: $23 \times 23 \mathrm{~mm}^{2}$, pixel size: $11.2 \times 11.2 \mu \mathrm{m}^{2}$ ), where high SStrs in the GL were expected (Figure $3 \mathrm{a}$ and $\mathrm{c}$ ). Reference images showing the initial condition at 20/95 were taken and the specimen mass was determined. Then, the specimens were split in groups of five specimens and exposed to $20^{\circ} \mathrm{C}$ and $40 \% \mathrm{RH}(20 / 40)$ in a climate chamber. After predefined intervals $(1,2,4,6,8,24,72$, and $144 \mathrm{~h})$, images were acquired and

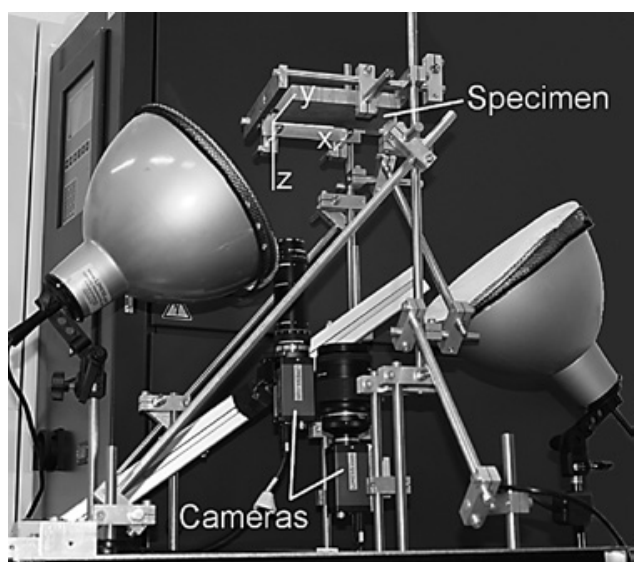

Figure 2: Test setup with specimen mount with two cameras and cold-light sources for DIC measurements.

a

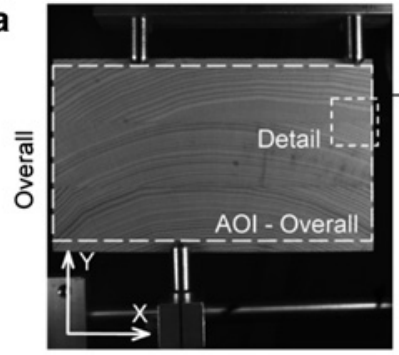

Climate change: $20 / 95 \rightarrow 20 / 40$

C
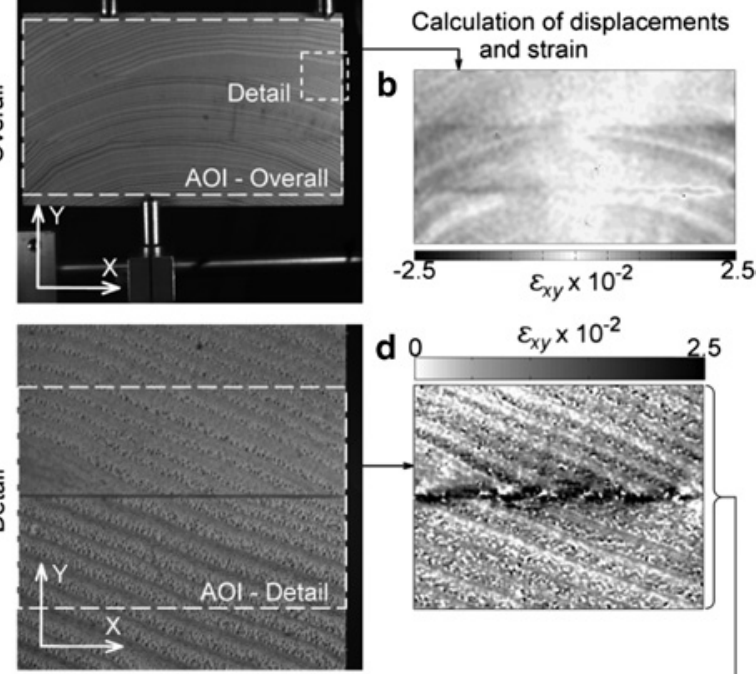

e
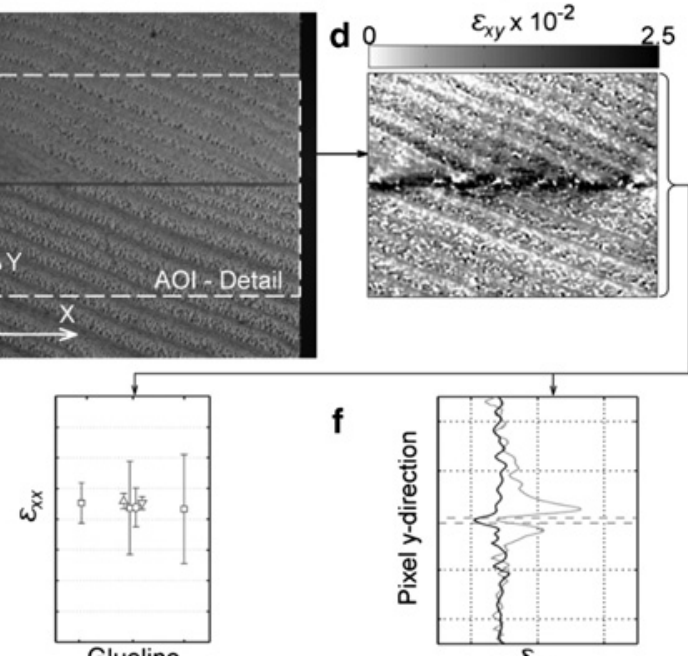

\section{f}

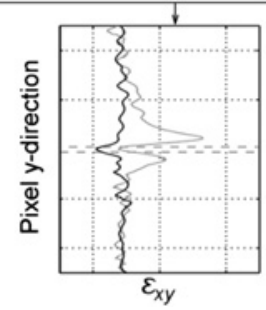

Figure 3: Overall view (a) and detailed view (c) of the specimens with definition of AOIs together with StrD after conditioning at 20/40 (b and d) and exemplary evaluation schemes (e and f).

the specimen mass was measured. Images were processed with the DIC software VIC 2D (Correlated Solutions, Inc., Columbia, SC, USA). The area of interest (AOI) was defined in the reference image for both views (Figure 3a and c) to narrow data down to the relevant content and to reduce file size and computing time. Based on the results from Valla et al. (2011), the parameters subset and step were specified in the software. Subset defines the size of a pixel array that is used to trace displacements between corresponding images based on the 
gray values of the speckle pattern and was assigned 21 (i.e., the array had a size of $21 \times 21$ pixels). For step, the values 3 for the overall view and 1 for the detailed view were selected. Step specifies the grid spacing; for example, step 3 means the correlations between images were calculated for every third pixel in the $\mathrm{x}$ - and $\mathrm{y}$-directions (Figure $3 \mathrm{a}$ and c). The in-plane displacements $u$ and $v$ in the $\mathrm{x}$ - and y-directions were determined by cross-correlating the images. Based on these displacement values, strain values $\varepsilon_{\mathrm{xx}}$ and $\varepsilon_{\mathrm{yy}}$ and SStrs $\varepsilon_{\mathrm{xy}}$ (in $\mathrm{mm} \mathrm{mm}^{-1}$; the results in the following sections are given without dimension) were calculated (Figure $3 \mathrm{~b}$ and $\mathrm{d}$ ). The choice of the respective AOI and step value resulted in strain field sizes of $620 \times 340$ for overall view and $1800 \times 1300$ for detailed view. To retrieve the strain values from the GL area and the wood, the data were further processed with MATLAB (The Mathworks, Inc., Natick, MA, USA; Figure 3e and f). The adhesive penetration behavior was evaluated by a reflected light microscope Leica MZ FLIII with the imaging software Leica Application Suite 4.1.0 (Leica Microsysteme Vertriebs GmbH, Wetzlar, Germany). For the observations in detailed view area, two specimens per adhesive and GL thickness were randomly selected.

\section{Results and discussion}

\section{Moisture content and strain development}

During climate change from 20/95 to 20/40, the mean MC decreased from $19.7 \%$ to $8.2 \%$ ( $\pm 0.1 \%$ ), which equals a mean MC change of $11.5 \%$. The most significant decrease of MC occurred within the first $24 \mathrm{~h}$ after exposure to 20/40 and was presumably caused by the rapid drying of the surfaces. A MC change of only approximately $1 \%$ was observed between 24 and $144 \mathrm{~h}$ until equilibrium MC (EMC) was very likely reached after $144 \mathrm{~h}$ (Figure 4). The decrease of MC

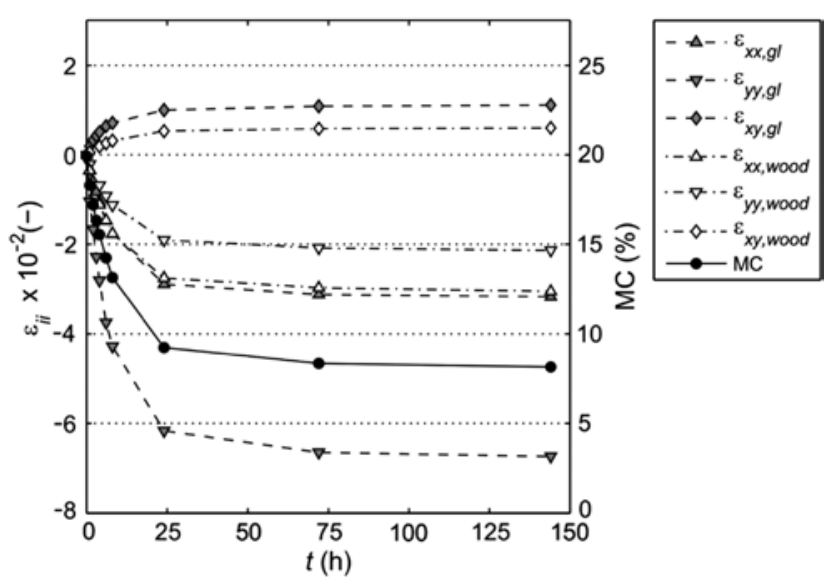

Figure 4: Development of MC over time after climate change from $20 / 95$ to $20 / 40$ together with development of strain $\varepsilon_{x x}, \varepsilon_{y y}$, and $\varepsilon_{x y}$ on specimen surfaces in wood (mean values from all wood surfaces from detailed view excluding the GL area) and in the GL area (mean values for one exemplary PRF GL). was accompanied by strain development. In Figure 4, the mean values for $\varepsilon_{\mathrm{xx}}, \varepsilon_{\mathrm{yy}}$, and $\varepsilon_{\mathrm{xy}}$ are presented over time separately for wood and one exemplary PRF GL. The strain values after $144 \mathrm{~h}$ for wood were retrieved from detailed view for all specimens and averaged $-0.0296( \pm 0.0029)$ for $\varepsilon_{\mathrm{xx}}$ and $-0.0203( \pm 0.0033)$ for $\varepsilon_{\mathrm{yy}}$. The negative values reflect the shrinkage deformation. The mean SStr $\varepsilon_{x y}$ after $144 \mathrm{~h}$ amounted to $0.0054( \pm 0.0019)$ and was mainly caused by the displacements of pixels in the $\mathrm{x}$-direction $(d u)$ relative to their y-position $(d y)$. The greater variation of $\varepsilon_{\mathrm{xy}}$ was possibly caused by an increased range of strain values covering high values in positions close to the GL and smaller values at some distance to the GL. In addition, a different deformation behavior between earlywood (EW) and latewood (LW) may have contributed to an increased variation of $\varepsilon_{\mathrm{xy}}$

The development of strain on wood surfaces is due to shrinkage and therefore correlated closely with the decrease of MC. The close relationship between MC and strain development also applies for the GL area. Thus, the most significant changes are seen within the first $24 \mathrm{~h}$ after exposure to 20/40, whereas the changes are lower later on.

From $\varepsilon_{\mathrm{xx}}, \varepsilon_{\mathrm{yy}}$, and $\varepsilon_{\mathrm{xy}}$ obtained after $144 \mathrm{~h}$, strain in the radial $\left(\mathrm{R} ; \varepsilon_{\mathrm{r}}\right)$ and $\mathrm{T}\left(\varepsilon_{\mathrm{t}}\right)$ directions were calculated by means of coordinate transformation:

$$
\begin{gathered}
\varepsilon_{\mathrm{t}}=\varepsilon_{\mathrm{xx}} \cos ^{2} \theta+\varepsilon_{\mathrm{yy}} \sin ^{2} \theta+2 \varepsilon_{\mathrm{xy}} \sin \theta \cos \theta \\
\varepsilon_{\mathrm{t}}=\varepsilon_{\mathrm{xx}} \sin ^{2} \theta+\varepsilon_{\mathrm{yy}} \cos ^{2} \theta-2 \varepsilon_{\mathrm{xy}} \sin \theta \cos \theta
\end{gathered}
$$

where $\theta$ is the angle between the $\mathrm{x}$-axis positioned at the wood-adhesive interface and the tangent aligned to the growth rings at the intersection point with the x-axis. As a result, $\varepsilon_{\mathrm{r}}$ and $\varepsilon_{\mathrm{t}}$ averaged $-0.0178( \pm 0.0027)$ and -0.0245 $( \pm 0.0037)$, respectively. For comparison, literature-based shrinkage values were collected for ash. For this evaluation, the differential shrinkage $\beta_{\mathrm{d}}$ in the $\mathrm{R}$ and $\mathrm{T}$ directions was first calculated based on the maximum shrinkage values $\beta_{\text {max }, \mathrm{r}}=5 \%$ and $\beta_{\text {max, }}=8 \%$ (Kollmann 1951) and a fiber saturation level of $\mathrm{MC}_{\mathrm{FS}}=32.2 \%$ for ash (Popper and Niemz 2009). The calculation resulted in differential shrinkage values $\beta_{\mathrm{d}, \mathrm{r}}=0.155 \% / \%$ and $\beta_{\mathrm{d}, \mathrm{t}}=0.248 \% / \%$ and consequently in $\beta_{\mathrm{r}, 1.5 \%}=1.78 \%$ and $\beta_{\mathrm{t}, 11.5 \%}=2.86 \%$ shrinkage for an MC change of $11.5 \%$. The comparison of experimental and literature-based values shows a good agreement of $\varepsilon_{\mathrm{r}}$ and $\beta_{\mathrm{r}, 11.5 \%}$, whereas $\varepsilon_{\mathrm{t}}$ was lower than $\beta_{\mathrm{t}, 11.5 \%}$. One reason for the difference between $\varepsilon_{\mathrm{t}}$ and $\beta_{\mathrm{t}, 11.5 \%}$ is likely due to the specimen design. In the case of MC change, the bonds between lamellas with mainly T-oriented growth rings cause a constraint situation predominantly in the $\mathrm{T}$ direction. Consequently, strain in the wood in the T direction is 
likely to be reduced due to this constraint. Furthermore, intraspecific variations in ash wood may have contributed to the observed difference.

\section{Strain distribution (StrD) in overall view}

The analyses in this and the following sections are based on strain values that were determined at the end of the $144 \mathrm{~h}$ test period, after an EMC at 20/40 was reached. In an overall view of AOI (Figure 3a), the differences in deformation behavior between samples bonded with different adhesives and GL thicknesses were minor. The representative StrDs for $\varepsilon_{\mathrm{xx}}, \varepsilon_{\mathrm{yy}}$, and $\varepsilon_{\mathrm{xy}}$ are displayed in Figure 5. The $\varepsilon_{\mathrm{xx}}$ StrD was homogeneous for the entire specimen surfaces (Figure $5 \mathrm{a}$ ). In contrast, pronounced differences were observed in $\varepsilon_{\mathrm{yy}}$ strain fields that can be explained by the shape and position of the growth rings (Figure $5 b$ ).

For comparison with strain values from the detailed view, the $\varepsilon_{\mathrm{xx}}$ and $\varepsilon_{\mathrm{yy}}$ values have been analyzed for wood areas (excluding the GLs) from the overall view. The mean $\varepsilon_{\mathrm{xx}}$ value amounted to $-0.0320( \pm 0.0024)$ and thus compared well to the mean $\varepsilon_{x x}$ from detailed view (-0.0296 $( \pm 0.0029)$. An even better agreement was found for the mean $\varepsilon_{\text {yy }}$ values with $-0.0202( \pm 0.0031)$ for overall view and $-0.0203( \pm 0.0033)$ for detailed view.

In both $\varepsilon_{\mathrm{yy}}$ and $\varepsilon_{\mathrm{xy}}$ strain maps, the position of the GLs could be visually identified (Figure $5 \mathrm{~b}$ and $\mathrm{c}$ ). However, no conclusive numerical analysis of strain in the GL was performed with overall view data. This is because the cross-correlation does not allow for a clear differentiation between wood and GL data in the case of the pixel size of $78.4 \times 78.4 \mu \mathrm{m}^{2}$ together with a higher grid spacing value (step: 3 ).

The $\varepsilon_{\mathrm{xy}}$ strain was inhomogeneously distributed in the $\mathrm{x}$-direction. In the center of the specimens, a white or light grayish zone could be observed, representing no or little SStr. The SStr increased toward both ends of the GL near the specimen sides. In the wood itself, strains correspond to the shape of the growth rings (i.e., with the wood structure). The highest SStr values are in and close to the GLs. This picture confirms that the test results comply with theoretical considerations with respect to specimen design. Normally, a reduction of MC in lamellas with T-oriented growth rings would lead to cupping of the cross-section because of different shrinkage in the $\mathrm{R}$ and $\mathrm{T}$ directions and the curvature of annual rings. The adhesive between the lamellas now prevents such deformations, causing restraints toward the edges of the specimens in the GL.

\section{Strains in glueline (GL) and wood in detailed view}

Strains in GLs have been retrieved from detailed view strain maps and analyzed depending on adhesive type
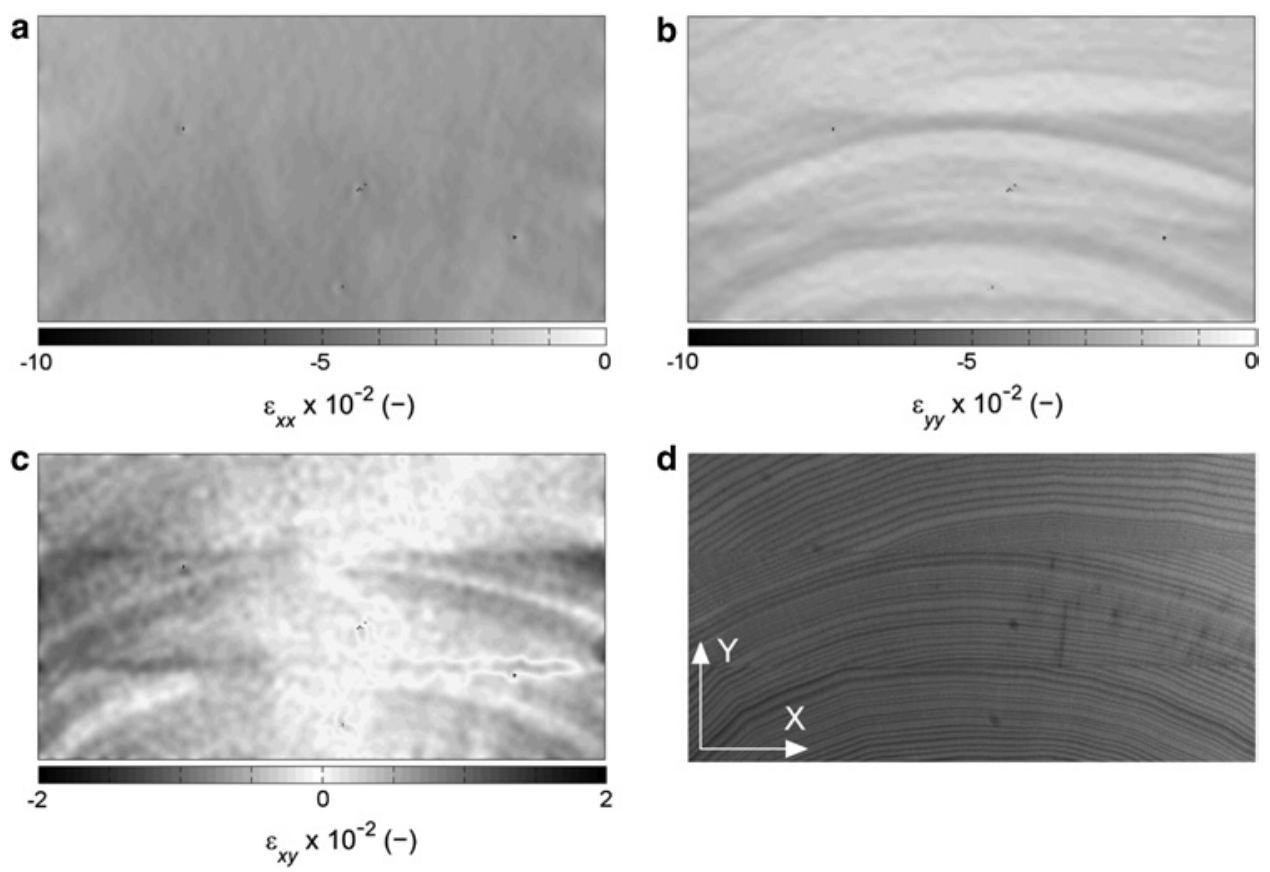

Figure 5: $\operatorname{StrD}$ for $\varepsilon_{x x}(a), \varepsilon_{y y}(b)$, and $\varepsilon_{x y}(c)$ from overall view AOI for one representative EPI-bonded sample together with the corresponding image of the test specimen before test (d). 

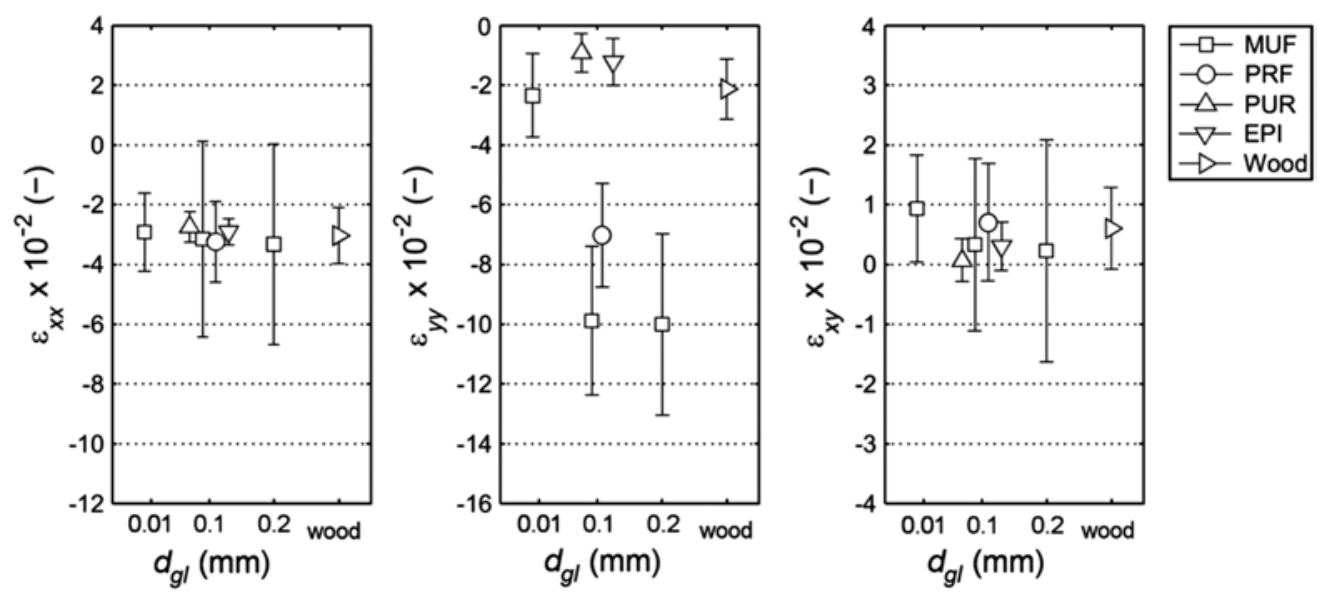

Figure 6: Strains $\varepsilon_{x x}, \varepsilon_{y y}$, and $\varepsilon_{x y}$ (mean and SD) in the GLs depending on adhesive and GL thickness and in wood.

and GL thicknesses. For comparison, strain values were also evaluated for the wood surfaces. The wood strain data were retrieved from a part of the AOI (Figure 3c) that was at least $2 \mathrm{~mm}$ away from the wood-adhesive interface and therefore were assumed not to be directly affected by the bond. The transition zone between wood and GL is not taken into account for evaluation in this section. For all samples, the mean strain values and SDs were calculated. The results are displayed in Figure 6. In addition, the samples were compared by means of variance analysis and the post hoc test Dunnett- $\mathrm{C}$, where required, at a 0.05 significance level.

The mean values for $\varepsilon_{\mathrm{xx}}$ ranged between - 0.0275 (PUR) and -0.0333 (MUF $\left.\mathrm{GL}_{0.2}\right)$ and therefore deviated only little from $\varepsilon_{\mathrm{xx}}$ for wood (-0.0305). The comparison of strain in the $\mathrm{x}$-direction in the GLs shows no statistical difference between the four adhesives as well as between the GL thicknesses. Also, as can be seen from Figure 6, strains $\varepsilon_{\mathrm{xx}}$ in the GL are about equal to the shrinkage strains in wood. Although differences between mean values were insignificant, the SD varied considerably for the samples. For EPI and PUR GLs, the SD was low and strain was more homogeneous than in wood. In contrast, MUF GLs, particularly those with 0.1 and $0.2 \mathrm{~mm}$ thickness, showed a high SD.

In the y-direction, strain varied considerably between the samples and can be divided into three groups (Figure 6). Strain $\varepsilon_{\mathrm{yy}}$ for the MUF $\mathrm{GL}_{0.01}$ $\left(\varepsilon_{\text {yy,mean }}=-0.0235\right)$ obviously was closely related to the behavior of the wood $\left(\varepsilon_{y y, \text { mean }}=-0.0214\right)$, and in a statistical sense, these two samples were similar. The closer examination of the images of MUF bonds with thin GL does not reveal a clear separation between wood and adhesive; thus, strain values represent a combined strain of adhesive with wood rather than for the isolated
MUF GL. A separate analysis of wood and adhesive for these samples would require significantly smaller pixel sizes than available in the present study. $\varepsilon_{\mathrm{yy}}$ strain values were more homogeneous for PUR and EPI GLs but significantly lower than for wood and MUF $\mathrm{GL}_{0.01}$. In contrast, strain in the y-direction was found to be significant for PRF with a mean $\varepsilon_{\mathrm{yy}}$ of -0.0703 and for MUF $\mathrm{GL}_{0.1}$ and $\mathrm{GL}_{0.2}$ with mean values of -0.0989 and -0.101 . One factor that most likely contributed to this considerable shrinkage is the water sorption behavior of adhesives that varies considerably depending on their chemistry. For example, Wimmer et al. (2013) determined significant water uptake for formaldehyde resins (MUF 22\% and PRF $18 \%$ ), whereas PUR only absorbed $3.5 \%$ for a humidity range between $0 \%$ and $98 \%$. In addition, formaldehyde resins are water based and moreover release water when curing. As bonding was performed at a relatively high wood MC, the water release from the GL may have been inhibited in the bonding process and cure shrinkage may have been limited. Postcuring shrinkage then may have occurred during conditioning at 20/40.

The mean SStr $\varepsilon_{\mathrm{xy}}$ ranged between 0.0093 for MUF $\mathrm{GL}_{0.01}$ and values close to zero, 0.00065 for PUR. Although $\varepsilon_{\mathrm{xy}}$ varied considerably between wood, adhesives, and GL thicknesses, no significant differences between the samples were found in a variance analysis. The SStr $\varepsilon_{\mathrm{xy}}$ for MUF $\mathrm{GL}_{0.01}$ was increased when compared to the strain level of wood and indicates elevated shear stress between the two adherends. In contrast, strain levels with $\mathrm{GL}_{0.1}$ and $\mathrm{GL}_{0.2}$ were similar (PRF) or significantly lower (MUF, PUR, and EPI) than in wood; therefore, a considerable influence of the GL is assumed.

In general, a higher SD of strain values could be observed for PRF and MUF bonds. This applies, in particular, for the $\mathrm{GL}_{0.1}$ and $\mathrm{GL}_{0.2^{2}}$ One reason for this is very 
likely that adhesives such as PRF or MUF can generate local strain maxima when compared to PUR because of different elasticities. This was found by Serrano and Enquist (2005) when comparing strain characteristics of adhesives with different stiffness in shear tests, and this can be confirmed in our tests when examining strain characteristics along the GL. However, Serrano and Enquist (2005) showed this behavior in tests with forces applied uniformly and parallel to the fiber direction, whereas strain in the present study was generated by the wood itself mainly due to shrinkage in the $\mathrm{R}$ and $\mathrm{T}$ directions. Therefore, the growth ring alignment and differences in shrinkage in the $\mathrm{R}$ direction within one growth ring, as determined by Lanvermann et al. (2014b) for spruce, may have influenced strain occurrences in our tests. In ash wood, differences within one growth ring with EW vessels with large diameters and fibers with thin cell walls and, in contrast, LW cells with small lumens and thick and stable cell walls are more distinctive than for spruce. These intra-ring variations of ash wood therefore may have generated more pronounced strain peaks along the GL than what for example may be induced with spruce. Furthermore, cracks were found in the MUF $\mathrm{GL}_{0.1}$ and $\mathrm{GL}_{0.2}$ most likely as a consequence of restrained shrinkage of the rigid adhesive. Although the frequency of cracks was significantly lower than in UF GLs as observed by Hass et al. (2012), cracks in the MUF GLs contributed to the increased strain variance. Localized strain maxima next to cracks are most likely associated with stress concentrations that may possibly act as starting points for bond failure and thus reduce bond strength.

\section{Shear strain distribution (SStrD) perpendicular to GL (detailed view)}

For a detailed analysis of $\operatorname{SStr} \varepsilon_{x y}$, average values were calculated across the detailed view AOI. The evaluation showed similar characteristics both for the distributions for PRF and MUF and for PUR and EPI. For reasons of clarity, only representative distributions that compare PUR and MUF as well as different GL thicknesses with MUF are displayed in Figure 7. The $\varepsilon_{x y}$ distributions exhibited a homogeneous strain level for the surfaces that are beyond the sphere of influence of the bond. With increasing proximity to the GLs, significant changes of $\varepsilon_{x y}$ can be found for some samples, thus indicating a considerable impact of the bond on the SStrD.

When comparing the behavior of GLs with the same thickness (Figure 7, left), considerable differences between MUF and PUR can be observed. For example, strain values for the MUF-bonded sample started deviating from the strain level of the wood in significant distance to the GL, whereas the PUR-bonded sample showed an effect only in close proximity to the GL. Also, a more pronounced strain decrease close to and in the GL could be found for MUF than for PUR. The minimum strain value in GL center, however, was lower for PUR than for MUF.

Obviously, the various adhesive types contributed to the differences in SStrD. For example, SStr in MUF bonds seems to be mainly distributed in the wood. This corresponds to theoretical considerations of Frihart (2009), who suggested that moisture-induced interfacial strain in PRF or MUF bonds is likely to be distributed in the

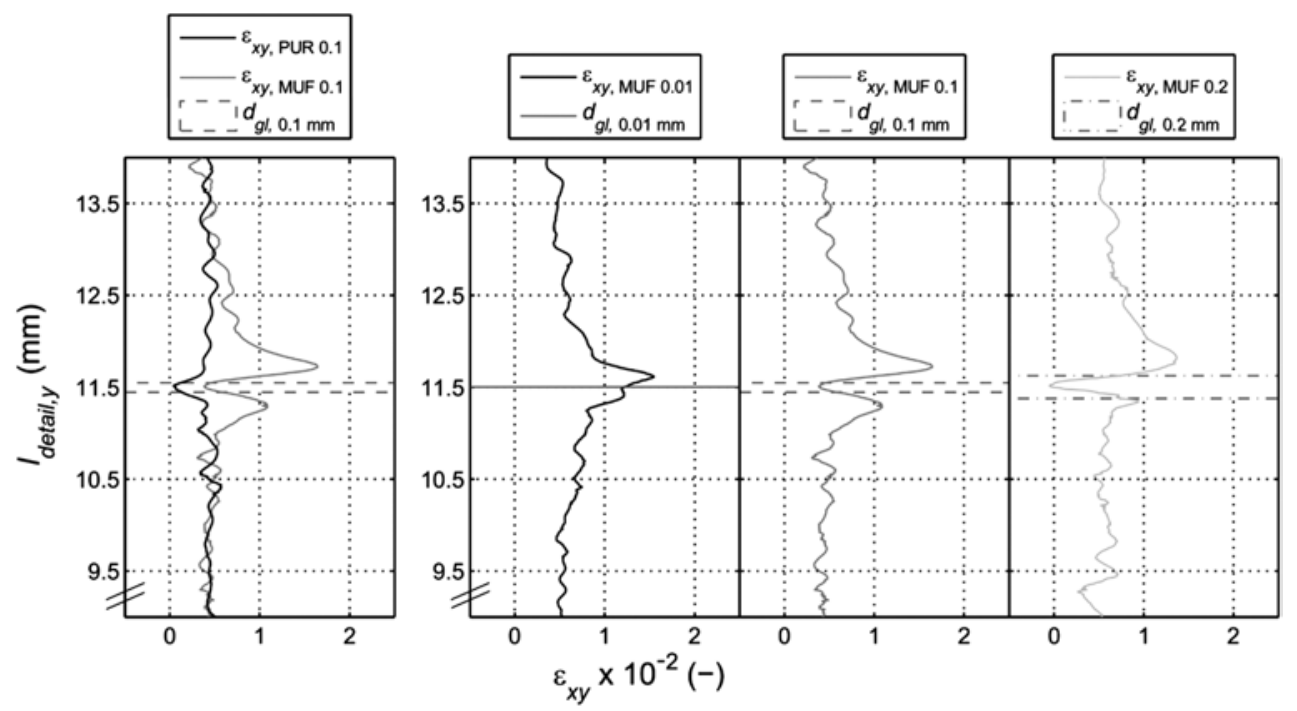

Figure 7: Representative $\operatorname{StrD} \varepsilon_{x y}$ in assemblies with homogeneous GL thickness for adhesive types MUF and PUR (left) and in MUF-bonded joints depending on $\mathrm{GL}$ thicknesses $d_{\mathrm{gl}} 0.01,0.1$, and $0.2 \mathrm{~mm}$ (right). 
wood and explained this with a stabilized wood surface due to the ability of these adhesives to penetrate into the cell walls together with a rigid GL where strain can barely be distributed. Referring to this, several research studies have shown that the stiffness of cured MUF and PRF adhesives is several times higher than of PUR or EPI (e.g., Konnerth et al. 2006; Clauß et al. 2011; Stoeckel et al. 2013) and, in addition, of ash wood in the $\mathrm{R}$ and $\mathrm{T}$ directions (Clauß et al. 2014). In contrast, only little effect on SStr can be found in the vicinity of the PUR GL. The reason for this is most likely that Young's moduli $(E)$ of EPI and PUR are similar or lower (e.g., $E_{\text {PUR }}=330 \mathrm{MPa}$ according to Clauß et al. 2011) than the elastic properties of ash wood in the $\mathrm{T}$ and $\mathrm{R}$ directions $\left(E_{\mathrm{t}}=578-625 \mathrm{MPa}\right.$ and $E_{\mathrm{r}}=1143-1193 \mathrm{MPa}$ as determined by Clauß et al. 2014) and therefore allow for a smoother strain transition. This aspect indicates that stress concentrations can be avoided with PUR and EPI. When comparing the distribution of moisture-induced strain of different adhesives in GL vicinity, the influence of adhesive penetration has to be considered as shown by Gindl et al. (2005) for PUR- and PRF-bonded spruce.

Furthermore, it needs to be taken into account that the adhesives in our survey were processed at high humidity and high wood MC; therefore, MUF and PRF polymers presumably contained a significant content of water. Water in the cured adhesive polymer was observed to act as a softener and to reduce the stiffness (Konnerth et al. 2010; Kläusler et al. 2013). Accordingly, this may have influenced strain occurrences for these adhesives, for example, in terms of an increased minimum strain value in GL center. In contrast, bonding at lower humidity and MC as applied in industrial production might prevent a reduced adhesive stiffness and lead to even more pronounced strain occurrences.

Looking only at SStrDs, one may conclude that EPI or PUR is more suitable for structural bonding. However, the application of EPI and in particular PUR also involves drawbacks such as limited resistance against moisture in the wood-adhesive interface. For example, Kläusler et al. (2014) observed a loss of adhesion in PUR bonds in wet condition along with regained bond strength in re-dried specimens. Therefore, it is difficult to draw a general conclusion about the suitability of adhesives based on the SStrD only.

The SStrDs for MUF bonds with $\mathrm{GL}_{0.01}, \mathrm{GL}_{0.1}$, and $\mathrm{GL}_{0.2}$ are significantly different (Figure 7, right). While increasing strain values were found for all thicknesses when approaching the GL, differences could be observed close to and in the GL. For $\mathrm{GL}_{0.01}$, no strain decrease was seen in the GL area, whereas a significant strain decrease adjacent and in the GL as well as a reduced strain level in the wood-adhesive interface were noticed for $\mathrm{GL}_{0.1}$ and $\mathrm{GL}_{0.2}$ bonds. Comparing $\mathrm{GL}_{0.1}$ and $\mathrm{GL}_{0.2}$, strain decrease seems to be more pronounced and a lower minimum strain value in GL center was found for $\mathrm{GL}_{0.2}$. This leads to the conclusion that the high adhesive stiffness relative to the wood has an increased effect on strain reduction in the GL center for a higher GL thickness. The direct strain transition together with comparatively high strain values indicates that the wood-adhesive interface in $\mathrm{GL}_{0.01}$ has to withstand stresses that are significantly higher than in the case of $\mathrm{GL}_{0.1}$ and $\mathrm{GL}_{0.2}$.

Although the effective stress levels cannot be quantified due to various reasons (e.g., microscale variabilities, relaxation, and plastic deformation), the different strain levels between the samples lead to the assumption that the GL thickness influences the MRD. These findings are a possible explanation for the dependence of MRD of ash bonds on GL thicknesses as determined by Knorz et al. (2014). Also, the results seem to be contrary to the common opinion that an ideal bond should exhibit a GL as thin as possible, at least when MRD testing is involved. As mentioned above, penetration possibly influences strain transition.

\section{SStrD in GL vicinity (detailed view)}

To evaluate further the dependence of $\operatorname{SStrD} \varepsilon_{\mathrm{xy}}$ in GL vicinity from the adhesive type, the distances on both sides of the GL were determined, where the $\varepsilon_{\mathrm{xy}}$ strain level

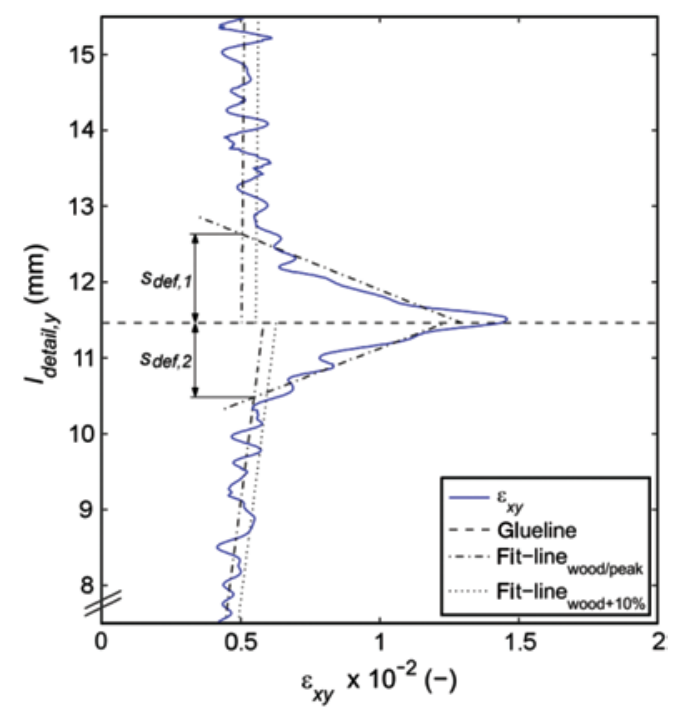

Figure 8: Distances $s_{\text {def, } 1}$ and $s_{\text {def, }}$ in GL vicinity where increased SStr are recorded, shown for a detailed view StrD of an exemplary MUF-bonded specimen with $0.01 \mathrm{~mm}$ GL. 


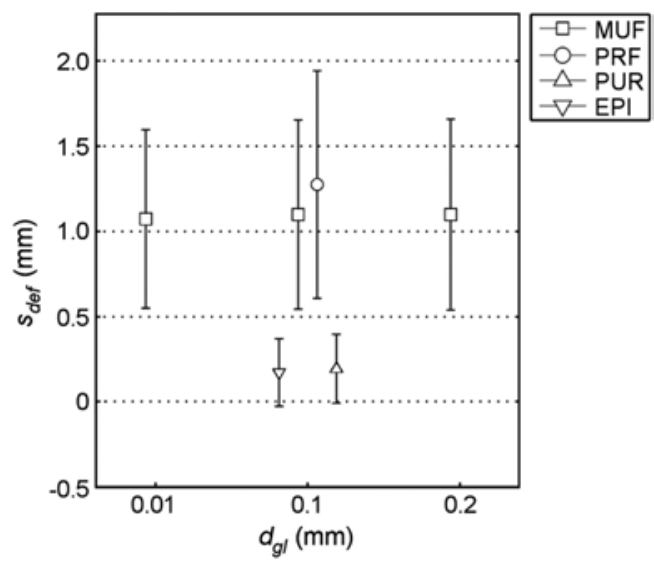

Figure 9: Distance $s_{\text {def }}$ (mean and SD) depending on adhesive and GL thickness.

adjacent to the GL deviated from the average $\varepsilon_{\mathrm{xy}}$ strain level in the wood. These regions with deviating strain level were regarded as influenced by the bond. Two distance values $s_{\text {def }, 1}$ and $s_{\text {def, }, 2}$ were determined for each GL based on the detailed view SStr diagrams (Figure 8 ). $s_{\text {def }}$ is the distance between GL and intersection point of $\varepsilon_{\mathrm{xy}}$ fit-lines for unaffected wood and the peak area. The beginning of the peak area was specified before as the intersection point of the $\varepsilon_{\mathrm{xy}}$ curve with $\varepsilon_{\mathrm{xy}}$ fit-line for wood increased by $10 \%$.

The mean distances $s_{\text {def }}$ together with their SD are displayed in Figure 9. These data for the four adhesives with $\mathrm{GL}_{0.1}$ show considerable differences between MUF $(1.1 \mathrm{~mm})$ and PRF $(1.28 \mathrm{~mm})$, on the one hand, and PUR $(0.19 \mathrm{~mm})$ and EPI $(0.17 \mathrm{~mm})$, on the other hand. This is supported by the statistical analysis, where these two groups were found to be significantly different, whereas the data within the groups were statistically similar (variance analysis with Dunnett-C post-hoc test, $p<0.05$ ).

Accordingly, this analysis confirms the observations in the previous section. The way of SStrD presumably varies with the elasticity of adhesives and their ability to diffuse into cell walls and stabilize them. The latter indicates that also the penetration behavior into the cell lumen network and from there into adjacent cell walls is of importance. Adhesive penetration as an influencing factor on StrD was also determined by Gindl et al. (2005), who found that the penetration of PUR and PRF mainly into spruce cell lumens changes the elastic properties of the wood-adhesive interphase and thus has an effect on StrD.

In this context, it would be important to know to which extent $s_{\text {def }}$ values can be explained by adhesive penetration into ash wood. For this reason, the lumen filling portion was observed by microscopy. In fibers of EW and LW, no or very little penetration (up to three cell layers) was found for all adhesives and GL thicknesses. In contrast, the penetration in EW vessels varied strongly with the adhesives. The lowest penetration for $\mathrm{GL}_{0.1}$ was found for MUF. Only individual vessels bordering the GL were filled with MUF adhesive and corresponded to a maximum penetration depth of $132 \mu \mathrm{m}$. Because long closed assembly times were used for both MUF and PRF, a limited penetration was expectable based on the data of Knorz et al. (2014). Nevertheless, the highest penetration depth in EW vessels of all adhesives was found in the case of PRF $(841 \mu \mathrm{m})$. The maximum penetration depths for PUR and EPI were 353 and $360 \mu \mathrm{m}$, respectively.

MUF bonds with different GL thicknesses showed statistically insignificant differences between $s_{\text {def }}$ values ( $\mathrm{GL}_{0.01} 1.07 \mathrm{~mm}, \mathrm{GL}_{0.1} 1.1 \mathrm{~mm}$, and $\mathrm{GL}_{0.2} 1.1 \mathrm{~mm}$ ). To obtain a thin GL, MUF bonds with $\mathrm{GL}_{0.01}$ were prepared with a shorter closed assembly time than bonds with $\mathrm{GL}_{0.1}$ or $\mathrm{GL}_{0.2}$ (Table 1). As a consequence of these varying bonding parameters, differences in adhesive penetration into EW vessels could be observed. For short closed assembly times, the adhesive penetrated up to $706 \mu \mathrm{m}$ into the EW vessel network. In contrast, only cut-open EW vessels that adjoined the GL were filled with adhesive (up to $132 \mu \mathrm{m}$ ) in the case of longer closed assembly times.

The $s_{\text {def }}$ values (i.e., the distances where strains are influenced by the bond) for MUF and PRF bonds were significantly higher than the maximum penetration depths of these adhesives. Thus, moisture-related strains extend deeper in the case of rigid adhesives than expectable by the sole penetration of the adhesives. In addition, $s_{\text {def }}$ values were similar for MUF $\mathrm{GL}_{0.01}, \mathrm{GL}_{0.1}$, and $\mathrm{GL}_{0.2}$, whereas penetration was significantly different. The previous data can be interpreted that SStrD in GL vicinity is independent from the penetration in EW vessels of ash. In contrast, the penetration depths for PUR and EPI exceed the mean $s_{\text {def }}$ values. This indicates that either the influence of penetrated vessels on strain is insignificant or that strain transition is, in general, smoother due to similar or lower elasticity of these adhesives when compared to ash wood perpendicular to the grain.

\section{Conclusions}

The deformation behavior of bonded ash was investigated by means of DIC while the specimens were dried from 20/95 to 20/40. The ash lamellas were bonded with the adhesives MUF, PRF, PUR, and EPI with $0.1 \mathrm{~mm}$ GL thickness. In addition, $\mathrm{GL}_{0.01}$ and $\mathrm{GL}_{0.2}$ have been prepared with MUF. 
DIC proved to be a valuable method to analyze 2D deformation on different scales. The analysis of strain in the GL in detailed view showed that $\varepsilon_{\mathrm{xx}}$ was significantly influenced by wood shrinkage. $\varepsilon_{\mathrm{yy}}$ differed strongly with adhesive and presumably depended on the ability of adhesives to absorb water or to store water from the preparation process.

SStrDs $\left(\varepsilon_{\mathrm{xy}}\right)$ were significantly different between rigid (PRF and MUF) and more elastic (PUR and EPI) adhesives. A more pronounced strain decrease in and close to the GL together with increased strain dissipation in wood regions was found for the rigid adhesives MUF and PRF.

A pronounced strain decrease was seen close to and in the MUF GL $\mathrm{L}_{0.1}$ and MUF $\mathrm{GL}_{0.2}$, whereas, for the MUF GL $\mathrm{L}_{0.01}$, a direct strain transition together with higher strain values was found. This indicates a higher stress in the case of a very thin GL, which possibly explains the lower resistance to delamination of thin GLs.

SStr for MUF and PRF bonds was predominantly distributed in the wood and influenced wood regions that were significantly beyond adhesive penetration depths and regions where adhesive diffusion may have stabilized cell walls. In contrast, SStrD in the wood was limited for PUR and EPI adhesives.

\section{References}

Aicher, S., Dill-Langer, G., Ranta-Maunus, A. (1998) Duration of load effect in tension perpendicular to the grain of glulam in different climates. Holz Roh- Werks. 56:295-305.

Angst, V., Malo, K. (2012) The effect of climate variations on glulam - an experimental study. Eur. J. Wood Wood Prod. 70:603-613.

Clauß, S., Gabriel, J., Karbach, A., Matner, M., Niemz, P. (2011) Influence of the adhesive formulation on the mechanical properties and bonding performance of polyurethane prepolymers. Holzforschung 65:835.

Clauß, S., Pescatore, C., Niemz, P. (2014) Anisotropic elastic properties of common ash (Fraxinus excelsior L.). Holzforschung 68:941-949.

EN 302-2 (2013) Adhesives for load-bearing timber structures - test methods. Part 2: determination of resistance to delamination. Comité Européen de Normalisation (CEN), Brussels.

EN 827 (2005) Adhesives - determination of conventional solids content and constant mass solids content. Comité Européen de Normalisation (CEN), Brussels.

Follrich, J., Stöckel, F., Konnerth, J. (2010) Macro- and micromechanical characterization of wood-adhesive bonds exposed to alternating climate conditions. Holzforschung 64:705.

Frihart, C.R. (2009) Adhesive groups and how they relate to the durability of bonded wood. J. Adhes. Sci. Technol. 23:601-617.

Frihart, C.R., Wescott, J.M. (2008) Why do some wood-adhesive bonds respond poorly to accelerated moisture-resistant tests?
In: $9^{\text {th }}$ Pacific Rim Bio-based Composites Symposium, Rotorua, New Zealand, pp. 51-58.

Gereke, T., Niemz, P. (2010) Moisture-induced stresses in spruce cross-laminates. Eng. Struct. 32:600-606.

Gindl, W., Dessipri, E., Wimmer, R. (2002) Using UV-microscopy to study diffusion of melamine-urea-formaldehyde resin in cell walls of spruce wood. Holzforschung 56:103.

Gindl, W., Schöberl, T., Jeronimidis, G. (2004) The interphase in phenol-formaldehyde and polymeric methylene di-phenyl-di-isocyanate glue lines in wood. Int. J. Adhes. Adhes. 24:279-286.

Gindl, W., Sretenovic, A., Vincenti, A., Müller, U. (2005) Direct measurement of strain distribution along a wood bond line. Part 2: effects of adhesive penetration on strain distribution. Holzforschung 59:307.

Hass, P., Wittel, F., Mendoza, M., Herrmann, H., Niemz, P. (2012) Adhesive penetration in beech wood: experiments. Wood Sci. Technol. 46:243-256.

Jönsson, J., Svensson, S. (2004) A contact free measurement method to determine internal stress states in glulam. Holzforschung 58:148-153.

Keunecke, D., Novosseletz, K., Lanvermann, C., Mannes, D., Niemz, P. (2012) Combination of X-ray and digital image correlation for the analysis of moisture-induced strain in wood: opportunities and challenges. Eur. J. Wood Wood Prod. 70:407-413.

Kläusler, O., Clauß, S., Lübke, L., Trachsel, J., Niemz, P. (2013) Influence of moisture on stress-strain behaviour of adhesives used for structural bonding of wood. Int. J. Adhes. Adhes. 44:57-65.

Kläusler, O., Hass, P., Amen, C., Schlegel, S., Niemz, P. (2014) Improvement of tensile shear strength and wood failure percentage of ${ }^{1} \mathrm{C}$ PUR bonded wooden joints at wet stage by means of DMF priming. Eur. J. Wood Wood Prod. 72:343-354.

Knorz, M., Schmidt, M., Torno, S., van de Kuilen, J.W. (2014) Structural bonding of ash (Fraxinus excelsior L.): resistance to delamination and performance in shearing tests. Eur. J. Wood Wood Prod. 72:297-309.

Knorz, M., Neuhaeuser, E., Torno, S., van de Kuilen, J.W. (2015) Influence of surface preparation methods on moisture-related performance of structural hardwood-adhesive bonds. Int. J. Adhes. Adhes. 57:40-48.

Kollmann, F. Technologie des Holzes und der Holzwerkstoffe Erster Band. Springer, Berlin/Göttingen/Heidelberg, 1951.

Konnerth, J., Jäger, A., Eberhardsteiner, J., Müller, U., Gindl, W. (2006) Elastic properties of adhesive polymers. Il. Polymer films and bond lines by means of nanoindentation. J. Appl. Polym. Sci. 102:1234-1239.

Konnerth, J., Gindl, W., Müller, U. (2007) Elastic properties of adhesive polymers. I. Polymer films by means of electronic speckle pattern interferometry. J. Appl. Polym. Sci. 103:3936-3939.

Konnerth, J., Stöckel, F., Müller, U., Gindl, W. (2010) Elastic properties of adhesive polymers. III. Adhesive polymer films under dry and wet conditions characterized by means of nanoindentation. J. Appl. Polym. Sci. 118:1331-1334.

Lanvermann, C., Sanabria, S.J., Mannes, D., Niemz, P. (2014a) Combination of neutron imaging (NI) and digital image correlation (DIC) to determine intra-ring moisture variation in Norway spruce. Holzforschung 68:113-122.

Lanvermann, C., Wittel, F., Niemz, P. (2014b) Full-field moisture induced deformation in Norway spruce: intra-ring variation of transverse swelling. Eur. J. Wood Wood Prod. 72:43-52. 
Marra, A.A. Technology in Wood Bonding. Principles in Practice. Van Nostrand Reinhold, New York, 1992.

Müller, U., Sretenovic, A., Vincenti, A., Gindl, W. (2005) Direct measurement of strain distribution along a wood bond line. Part 1: shear strain concentration in a lap joint specimen by means of electronic speckle pattern interferometry. Holzforschung 59:300-306.

Niemz, P., Bärtschi, H., Howald, M. (2005) Untersuchungen zur Feuchteverteilung und Spannungsausbildung in Holzbauteilen bei Wechselklimalagerung [Investigation of moisture distribution and stress formation in timber construction materials under changing climatic conditions]. Schweiz. Zeitsch. Forstw. 156:92-99.

Ohnesorge, D., Richter, K., Becker, G. (2010) Influence of wood properties and bonding parameters on bond durability of European beech (Fagus sylvatica L.) glulams. Ann. For. Sci. 67.

Popper, R., Niemz, P. (2009) Wasserdampfsorptionsverhalten ausgewählter heimischer und überseeischer Holzarten. Bauphysik 31:117-121.

Schmidt, M., Glos, P., Wegener, G. (2010) Gluing of European beech wood for load bearing timber structures. Eur. J. Wood Wood Prod. 68:43-57.
Serrano, E., Enquist, B. (2005) Contact-free measurement and nonlinear finite element analyses of strain distribution along wood adhesive bonds. Holzforschung 59:641-646.

Stoeckel, F., Konnerth, J., Gindl-Altmutter, W. (2013) Mechanical properties of adhesives for bonding wood - a review. Int. J. Adhes. Adhes. 45:32-41.

Valla, A., Konnerth, J., Keunecke, D., Niemz, P., Müller, U., Gindl, W. (2011) Comparison of two optical methods for contactless, full field and highly sensitive in-plane deformation measurements using the example of plywood. Wood Sci. Technol. 45:755-765.

van de Kuilen, J.W., Gard, W.F. (2013) Damage assessment and residual service life estimation of cracked timber beams. Adv. Mater. Res. 778:402-409.

Wimmer, R., Kläusler, O., Niemz, P. (2013) Water sorption mechanisms of commercial wood adhesive films. Wood Sci. Technol. 47:763-775.

Zink, A., Davidson, R., Hanna, R. (1995) Strain measurement in wood using a digital image correlation technique. Wood Fiber Sci. 27:346-359. 